\title{
Research on high water temperature of diesel engine and improvement of radiator
}

\author{
Huang Jian
}

\author{
Guangxi Technological College of Machinery and Electricity \\ Department of Automobile Engineering \\ 346591653@163.com
}

Keywords: Diesel engine,coolant temperature too high, improvement, aluminum radiator.

\begin{abstract}
For a water-cooled engine, radiator performance has a direct impact on automobile engine heat dissipation effect, influence the automobile's power performance, economy and reliability. Based on the 6DL engine high temperature problems are investigated, analyzed the reasons of high temperature of the engine coolant radiator, developed three sets of technical improvement scheme, through testing, comparison, comprehensive consideration of technology, economy and other factors, determines the transformation scheme of aluminum radiator.
\end{abstract}

\section{Introduction}

As much more compact design and larger unit volume power adopted for modern automobile engine, the enhancement degree become higher and higher, and the density of heat flow occurred by engine is also increased obviously. At present, almost the reinforcement of all engines are faced with how to resolve the cooling and heat balance problem under high power density. The engine cooling system of heavy vehicle needs to meet the supporting requirement of whole vehicle in spite of maintaining the needs of engine itself. Due to the limit of structure arrangement, the design and installation of cooling element often can not reach the ideal status. As the supporting performance is not good, and the cooling capacity can not well adapt to the working condition and climate, high water temperature or even "Boil" phenomenon is usually happened. Therefore, the system element must be matched with the whole vehicle, especially radiator and fan. Moreover, the wind resistance of radiator element shall be small, and the high speed air flow shall be enough with higher heat exchange efficiency. To develop effective and reliable cooling system has become a key technical problem to increase power and improve economy of engine.

\section{Investigation of high water temperature of diesel engine}

Technical parameter of 6DL engine. The model of diesel is CA6DL1-28, which has several types, such as 6 cylinders, straight, direct injection, supercharged and charge air cooling. The main technical features are high power, covers $191-235 \mathrm{~kW}(260-320 \mathrm{Ps})$, which can meet the requirement of current mainstream of heavy vehicle; long lifetime; low discharge (which can meet the requirement of European II and III, with potential of European IV ); Low oil consumption (the minimum oil consumption is $193 / \mathrm{kW} . \mathrm{h}$ ) and low noise (noise of whole vehicle: $96.5 \mathrm{~dB}(\mathrm{~A})$. The requirements of engine working temperature are as follows:

\begin{tabular}{|c|c||}
\hline Normal working water temperature & $80 \sim 100^{\circ} \mathrm{C}$ \\
\hline \hline Optimal working water temperature & $90 \sim 95^{\circ} \mathrm{C}$ \\
\hline \hline Highest working water temperature limit & $105 \sim 107^{\circ} \mathrm{C}$ \\
\hline
\end{tabular}

2. Investigation of high water temperature of $6 \mathrm{DL}$ engine 


\begin{tabular}{|c|c||}
\hline $\begin{array}{c}\text { Cangzhou district of } \\
\text { Hebei }\end{array}$ & $\begin{array}{l}\text { As the temperature is increasing in May, the water temperature of vehicle also } \\
\text { become too high, water temperature of empty vehicle running in flat area can } \\
\text { reach } 80-90^{\circ} \mathrm{C} \text {, which can arrive } 100^{\circ} \mathrm{C} \text { during climbing under heavy load. }\end{array}$ \\
\hline \hline Hebei & $\begin{array}{c}\text { The water temperature of truck carried coal with total weight of } 55 \text { Tons running } \\
\text { on flat road from Shanxi, Neimeng, Ningxia to Hebei and Shandong is about } \\
95^{\circ} \mathrm{C}, \text { boil phenomenon will be happened when it is climbing. }\end{array}$ \\
\hline \hline Shanxi & $\begin{array}{l}\left.\text { Under highest temperature in summer (37 }{ }^{\circ} \mathrm{C}\right), \text { the water temperature of a } 310 \mathrm{HP} \\
\text { motor tractor with total weight ( tractor and goods) of } 55 \text { Tons is on red area, boil } \\
\text { phenomenon is happened when it is climbing. }\end{array}$ \\
\hline Anyang, Henan & $\begin{array}{l}\text { The cooling water tank of engine is too thin, so high temperature is easy to be } \\
\text { happened for engine. }\end{array}$ \\
\hline \hline Dezhou, Anhui & $\begin{array}{l}\text { Water tank of } 260 \text { and } 280 \mathrm{HP} \text { engine is small, but the water temperature of } \\
\text { engine is high. }\end{array}$ \\
\hline
\end{tabular}

\section{Cause analysis of high water temperature in 6DL engine}

Coolant inspection. After inspecting the working procedure of adding coolant for general assembly line, we found a situation, the worker only added anti freezing solution in one half of capacity with running water in another half, so the anti freezing solution is diluted. According to the inspection of Quality Assurance Department, the boiling point of anti freezing solution is reduced to $104^{\circ} \mathrm{C}$ (over) , which is one of causes to result in boil phenomenon of water tank.

Inspection of radiator core fin for water tank and intercooler. Water tank of vehicles with problems is required to be thoroughly cleaned by users through a high pressure water gun from inside to outside at first, so as to inspect whether the big wind resistance and poor heat dissipation are caused by stolen goods blocked in radiator core fin or intercooler radiator core fin. According to tracking test, the water temperature is still high, so this factor can be excluded consequently.

Inspection of water pump and fan of engine. After the test, we found the water pump worked normally, and the tension of belt also met the requirement. The radiator fan of vehicle with problem is not damaged after inspection, so the insufficient working ability of water pump and engine fan to cause high water temperature can be also excluded.

Thermostat performance inspection. After inquiry of technicians, the engine with such model of vehicle was on a state of small circulation when the water temperature of engine was lower than $76^{\circ} \mathrm{C}$, the thermostat was opened automatically if the water temperature arrived $76^{\circ} \mathrm{C}$, and it was fully opened for big circulation when the water temperature reached $86^{\circ} \mathrm{C}$. Based on thorough inspection and measurement on engines of vehicle with high water temperature by technicians, we found that, the thermostat worked normally, and the temperature of big and small circulation of engine was consistent with above condition as well, so this factor can be excluded, too.

Dimension comparison inspection of radiator. Understood from dealer, some users installed water spraying device for water tank or changed a bigger water tank, the temperature for running on flat road kept at $85^{\circ} \mathrm{C}$ or so, and boil phenomenon was never happened even though it was climbing, which solved the problem of high water temperature. According to benchmarking with radiator of other automobile factory which has the engine with same horsepower, we found that the heat radiating area of defective vehicles was very small. This is the main cause of high water temperature of 6DL engine. 


\section{Solution formulation of high water temperature in 6DL engine}

Further improvement of heat dissipation capability for radiator is required to solve high water temperature for defective vehicles. Comprehensively considering cost, technical difficulty, efficiency and other factors, the concept of design improvement is mainly to increase heat radiating area and improving the structure or material of radiator. Thus, three alternative schemes are made with relative test as following.

\section{Increase heat radiating area by lengthening the radiator core size}

Key point of scheme 1. Increase the height of radiator core by $130 \mathrm{~mm}$ and increase the total heat radiating area by $17 \%$.

Advantage of this scheme. Directly increase the frontal area and radiating area of radiator and reduce the wind resistance, which is conducive to reduce the power loss of engine fan and increase the heat dissipating capacity.

Sample of this scheme is installed on sample vehicle, which is arranged to make climbing contrast test in Meng Mountain. The sample vehicle is loaded and the total weight is 55 Tons. Please find the test result from following table:

\begin{tabular}{|c|c|c|c||}
\hline Project & Original radiator & Radiator in scheme 1 & Comparison \\
\hline $\begin{array}{c}\text { Water temperature when } \\
\text { running on flat road }\end{array}$ & $87 \sim 91^{\circ} \mathrm{C}$ & $83 \sim 86^{\circ} \mathrm{C}$ & Decrease about $5^{\circ} \mathrm{C}$ \\
\hline \hline $\begin{array}{c}\text { Water temperature } \\
\text { during climbing }\end{array}$ & $95 \sim 98^{\circ} \mathrm{C}$ & $90 \sim 93^{\circ} \mathrm{C}$ & Decrease about $5^{\circ} \mathrm{C}$ \\
\hline
\end{tabular}

Conclusion: Under same working condition as original radiator, the radiator in scheme 1 is able to reduce the water temperature by $5^{\circ} \mathrm{C}$ approximately, which has a good heat dissipation effect. However, considering the cab of each model of vehicle is installed very lower, the increasing height $(130 \mathrm{~mm})$ of radiator will be made downward. After test, the clearance between the bottom of radiator and ground is only $300 \mathrm{~mm}$ when the vehicle is shaking with heavy load, which may lead to lower passing ability of whole vehicle. Therefore, scheme 1 is not the preferred option.

\section{Increase heat radiating area for water tank by thickening core size of radiator}

Key point of scheme 2. Change radiator from three rows of tubes into four rows of tubes, decrease the height of radiator by $70 \mathrm{~mm}$ and increase the heat dissipation area by $21 \%$.

Advantages of this scheme. In spite of reducing the height of radiator, it can obviously increase the area of heat dissipation at the same time, which can improve the passing ability of whole vehicle without involving the change of arrangement for the whole vehicle. The sample of such scheme has been done with radiator wind tunnel laboratory test, please find the result as following:

\begin{tabular}{||c||c||}
\hline Project & Comparison with radiator in Scheme 2 of original radiator \\
\hline $\begin{array}{c}\text { Average heat dissipating capacity of each } \\
\text { working point }\end{array}$ & Increase $7 \%$ \\
\hline \hline Wind resistance & Increase $45 \sim 60 \%$ \\
\hline
\end{tabular}

Conclusion: Compared with original radiator, the heat dissipating capacity of radiator in scheme 2 only increases $7.5 \%$ under same using condition, but the wind resistance increases $45-60 \%$. The effect of heat dissipation is not obvious. Simultaneously, as the structure of radiator in this scheme shall be changed, so the cost will be increased relatively, the economy is poor, so scheme 2 is infeasible.

As the above schemes to directly increase the area of heat dissipation are not passed, it is necessary to improve the radiator from the aspect of material. 
There are two kinds of material used for automobile radiator: copper and aluminum. The former is generally used for passenger car, while the latter is often used for large commercial vehicle. At present, the developing direction of automobile technology is light, high efficiency and economic, so the material and manufacturing process are also constantly adapt to new requirement. Under the premise of ensuring adequate cooling capacity and strength, small volume, light weight and higher heat dissipating efficiency become the developing trend of radiator.

\section{Change original copper radiator into aluminum radiator}

With its obvious advantages of light material and rich resource, aluminum radiator is widely used in foreign cars, which has gradually replaced copper radiator in domestic cars and light vehicles as well. Although copper radiator is mainly used to bus, engineering machinery and heavy truck, aluminum radiator manufactured by brazing is increasing gradually from the development prospect of automobile radiator.

Key point of Scheme 3: Increase the area of heat dissipation by changing the original copper radiator into aluminum radiator, thickening heat dissipation core from $50 \mathrm{~mm}$ to $68 \mathrm{~mm}$, and increasing clearance between fins without adding wind resistance or changing the overall size of radiator.

Advantages of this scheme: Without changing the overall size of radiator or arrangement of the whole vehicle, it is able to increase the area of heat dissipation, improve heat dissipating capacity and thus resolve the problem of high water temperature by changing material and improving inside structure. At the same time, as the price of aluminum is lower than that of copper, and the weight of aluminum radiator is reduced by $25 \sim 40 \%$, this scheme can reduce the manufacturing cost and improve the economy.

Samples of this scheme have been done with wind tunnel laboratory test and heavy loading tests by climbing long slope, the test results are shown as below:

\begin{tabular}{|c||c||}
\hline Project & Comparison with radiator in scheme 2 of original radiator \\
\hline $\begin{array}{c}\text { Average heat dissipation for each } \\
\text { working point }\end{array}$ & Increase $20 \%$ \\
\hline Water temperature during climbing & Reduce $6 \sim 7^{\circ} \mathrm{C}$ \\
\hline \hline
\end{tabular}

Conclusion: After improvement, the heat dissipation capacity increased $20 \%$ than before, and the water temperature of water tank during climbing also decreased $6 \sim 7^{\circ} \mathrm{C}$ than before. Thus, it is able to keep the engine temperature of vehicles with improved radiator at $88 \sim 91{ }^{\circ} \mathrm{C}$ under high temperature environment, so that the engine can work in the range of optimal working water temperature. This scheme resolved the problem of high water temperature very well.

Comparison of three schemes:

\begin{tabular}{|c|c|c|c|}
\hline No. & Thought of scheme & Content of scheme & Feasibility analysis \\
\hline Scheme 1 & $\begin{array}{l}\text { Increase heat radiating area by } \\
\text { lengthening the radiator core } \\
\text { size }\end{array}$ & $\begin{array}{l}\text { Increase the height of radiator core } \\
\text { by } 130 \mathrm{~mm} \text { and increase the total } \\
\text { heat radiating area by } 17 \% \text {. }\end{array}$ & $\begin{array}{l}\text { It is infeasible because of lower } \\
\text { passing ability. }\end{array}$ \\
\hline Scheme 2 & $\begin{array}{l}\text { Increase heat radiating area for } \\
\text { water tank by thickening core } \\
\text { size of radiator }\end{array}$ & $\begin{array}{l}\text { Change radiator from three rows of } \\
\text { tubes into four rows of tubes, and } \\
\text { decrease the height of radiator by } \\
70 \mathrm{~mm} \text {. }\end{array}$ & $\begin{array}{l}\text { It is infeasible because of too big wind } \\
\text { resistance after test in laboratory. }\end{array}$ \\
\hline Scheme 3 & $\begin{array}{l}\text { Change copper radiator into } \\
\text { aluminum radiator }\end{array}$ & $\begin{array}{l}\text { Change to use aluminum radiator, } \\
\text { change the size of heat dissipation } \\
\text { core from } 50 \mathrm{~mm} \text { to } 68 \mathrm{~mm} \text {, and } \\
\text { increase the clearance between fins. }\end{array}$ & $\begin{array}{l}\text { This scheme has good feasibility, as it } \\
\text { increases the area of heat dissipation } \\
\text { without changing the overall size. }\end{array}$ \\
\hline
\end{tabular}




\section{Conclusion}

According to the inspection, test and technical analysis, we have clearly understand that, the high water temperature in engine is caused by small heat dissipating capacity of radiator, so the key to resolve this problem is to increase the heat dissipating capacity of radiator. Focusing on deep test, analysis, demonstration and comparison of feasibility and economical efficiency of those three schemes, finally we decide to change aluminum radiator, which can not only fundamentally solve the problem of high water temperature in big horsepower engine of our factory, but also help us to reduce the production cost and achieve good benefit.

\section{References}

[1] Zhang Xingzhou, Ma Chongfang, Simulation research on characteristics of automobile engine radiator, [J]Engine for vehicle, 2005/04

[2] Jiang Zhiqing, Design and research of diesel cooling system, [J] Manufacturing automation, 2008/03

[3] Zhang Min, Design and development of automobile radiator [J]. Tianjin Automobile, 2002(03)

[4] Zhao Jun, Design improvement and experimental study of cooling system for heavy vehicles,

[J] Design and manufacture of diesel engine , 2008/03;

[5] Huang Hui, Automobile radiator material and its manufacturing technology, [J] Bus technology and research, 2006/04; 